\title{
MALE INFERTILITY IN SPINAL CORD TRAUMA
}

\author{
CRISTIANO UTIDA, JOSE C. TRUZZI, HOMERO BRUSCHINI, ROGERIO SIMONETTI, \\ AGNALDO P. CEDENHO, MIGUEL SROUGI, VALDEMAR ORTIZ
}

\author{
Department of Urology, Paulista School of Medicine, Federal University of Sao Paulo, UNIFESP, and \\ Section of Urology, San Francisco Home School, Sao Paulo, Brazil
}

\begin{abstract}
Every year there are 10 thousand new cases of patients victimized by spinal cord trauma (SCT) in the United States and it is estimated that there are 7 thousand new cases in Brazil. Eighty percent of patients are fertile males. Infertility in this patient group is due to 3 main factors resulting from spinal cord lesions: erectile dysfunction, ejaculatory disorder and low sperm counts. Erectile dysfunction has been successfully treated with oral and injectable medications, use of vacuum devices and penile prosthesis implants. The technological improvement in penile vibratory stimulation devices (PVS) and rectal probe electro-ejaculation (RPE) has made such procedures safer and accessible to patients with ejaculatory dysfunction. Despite the normal number of spermatozoa found in semen of spinal cord-injured patients, their motility is abnormal. This change does not seem to be related to changes in scrotal thermal regulation, frequency of ejaculation or duration of spinal cord damage but to factors related to the seminal plasma. Despite the poor seminal quality, increasingly more men with SCT have become fathers through techniques ranging from simple homologous insemination to sophisticated assisted reproduction techniques such as intracytoplasmic sperm injection (ICSI).
\end{abstract}

Key words: spinal cord injuries; semen; infertility, male; ejaculation; paraplegia

Int Braz J Urol. 2005; 31: 375-83

\section{INTRODUCTION}

In the United States, there are approximately 300,000 patients with sequelae from spinal cord trauma (SCT), and there are a reported 10,000 new cases every year (1). In Brazil, an estimated 7 thousand new cases occur every year. Approximately $80 \%$ of the affected patients are males of reproductive age. Men with SCT often present fertility problems related to the neurological lesion. This patient group faces 3 main problems concerning this issue (1-5): first, erectile dysfunction, where both medical and surgical treatment has provided a high resolution in- dex; second, ejaculatory dysfunction, present in up to $90 \%$ of the cases and requiring the use of resources for inducing semen release; and finally, low sperm counts. The number of spermatozoa in the ejaculate of spinal cord-injured patients is generally within normal ranges. However, motility is low, approximately $20 \%$ as compared to the $70 \%$ rate usually found in healthy patients. Infertility among spinal cord-injured patients usually results from the sum of all these factors. This present report aims to provide a critical analysis of each involved factor, the pathophysiology and the currently available treatment modalities. 


\section{ERECTILE DYSFUNCTION}

The change of erectile quality in the spinal cord-injured patient is directly related to the lesion level and the extent of impairment. Two components act together in the erectile physiology: the reflex and the psychogenic components (6). The reflex component is induced by tactile stimulation of the genital organs; impulses run through the pudendal nerve (somatic innervation) until they reach the sacral erection center. The parasympathetic nuclei are activated and erection is achieved through the cavernous nerves. On the other hand, psychogenic stimulation results from audio-visual or imaginary stimuli and depends on the modulation of the spinal erection centers (T11-L2 and S2-S4). In order to activate the erection process, cerebral impulses are transmitted through the sympathetic (inhibiting norepinephrine release), parasympathetic (releasing nitric oxide and acetylcholine) and somatic (releasing acetylcholine) tracts.

When the lesion occurs at the sacral level, the psychogenic erection component is preserved but the reflex mechanism is not. Under these circumstances, the cerebral stimulus is transmitted through sympathetic fibers thus inhibiting the norepinephrine release, while acetylcholine and nitric oxide are released through synapses existing in somatic and postganglionic parasympathetic neurons. When compared with sacral fibers, the lower number of synapses between thoracic-lumbar fibers and postganglionic parasympathetic neurons results in partial erection. In patients with spinal cord lesion above the T9 level, psychogenic erection is usually absent $(1,6)$.

\section{Treatment of Erectile Dysfunction}

The first step consists of orientating the patient about the impact of SCT on sexual dysfunction and the types of erection he can possibly achieve.

Before treatment, it is fundamental that patients be instructed to empty their bladders prior to initiating the sexual stimulation. This maneuver aims to avoid the occurrence of autonomic dysreflexia (AD) $(7,8)$.

Therapeutic options for erectile dysfunction (9-20) in these patients include the use of oral medi- cation, intracavernous injection, vacuum devices and penile prostheses. The selection of the type of treatment depends on adaptation and individual response to the selected modality, though it should always start with the less invasive methods.

Sildenafil, an oral medication introduced in the market approximately 6 years ago, is a potent inhibitor of type-5 phosphodiesterase (PDE5), responsible for degradation of cyclic guanosine monophosphate (cGMP). Sildenafil enhances the relaxing effect of nitric oxide (NO) released in response to sexual stimulation by increasing cGMP concentrations in the cavernous body. This results in increased penile rigidity and tumescence. Success rates among spinal cord-injured patients range from 75 to $94 \%$ (10-12). For the majority of writers, the best results are achieved by patients with partial neurological damage. On the other hand, Sanchez Ramos et al. (11) demonstrated that there was no difference in the response to medication when comparing either the severity of neurological impairment or the level of spinal cord lesions. Adverse effects resulting from Sildenafil use among patients with SCT do not differ from those observed in the general population and range from 10 to $42 \%$. Headaches (17\%) and face rubor are among the most frequent side effects (12). Tadalafil and vardenafil, 2 other inhibitors of phosphodiesterase that have been more recently used, produce effects similar to Sildenafil in spinal cord-injured patients $(9,10,13)$.

Apomorphine, a dopaminergic agonist, acts by stimulating the $\mathrm{D} 2$ receptors in the paraventricular nucleus of the hypothalamus. This activates pro-erectile central pathways involving NO and oxytocin, thus leading to erection $(10,14)$. The only study on the efficacy of apomorphine for erectile dysfunction in spinal cord-injured patients was performed by Strebel et al. (14). Only 2 out of 22 patients presented satisfactory erections following the use of sublingual apomorphine.

Intracavernous injections of vasoactive substances provide a success rate of $95 \%$, defined by achievement of an erection suitable for penetration $(15,16)$. Treatment should start with low dosing due to the risk of priapism (papaverine $7.5 \mathrm{mg}$, or prostaglandin E1 $2 \mu \mathrm{g}$ ). In addition to priapism, other po- 
tential complications for this treatment modality include penile excoriation, infection and fibrosis of the cavernous body.

Vacuum devices $(17,18)$ promote an increase in penile blood flow due to the negative pressure they generate. Once the erection is obtained, a constriction ring is placed at the base of the penis. Patients should not keep this ring in place for more than 30 minutes due to the risk of ischemic penile damage. Denil et al. (17) assessed 20 patients with SCT using vacuum devices. After 3 months, $93 \%$ of the men reported proper erections, but this index decreased to $41 \%$ after 6 months, with the most frequent complaint being early loss of erection rigidity. Its use is contraindicated in patients with blood dyscrasias, or those using anticoagulants due to complications such as ecchymoses, skin edema and abrasions.

The implantation of a penile prosthesis (19) is usually the last therapeutic option, and is attempted when all previously described techniques have failed. There is a wide range of materials and models that adapt to each patient's condition and needs. Semi-rigid prostheses have the advantage of easy implantation, a low mechanical failure rate and low cost. The disadvantages are that the penis remains constantly in an erect position, in addition to presenting a higher risk of penile erosion. Inflatable prostheses promote an appearance more resembling that of a normal erection, however their implantation is more laborious and costs are quite high. In patients with SCT, the penile prosthesis aims also to assist in the management of urinary incontinence, making the adaptation of external penile collectors easier (20). Kimoto \& Iwatsubo (20) assessed 82 spinal cord-injured patients. Follow-up time ranged from 1 to 10 years (mean 4 years) and obtained a satisfaction rate of $64 \%$ for sexual function and $93 \%$ for adaptation of the urine collector. Complications occurred in $13.3 \%$ of cases, with the most frequent being extrusion of the prosthesis and cavernous infection.

\section{EJACULATORY DYSFUNCTION}

Ejaculatory dysfunction is one of the main factors for infertility in patients victimized by SCT
$(1,3-5,21)$. In 1948, Horne et al. (3) reported that ejaculation was present in only $18 \%$ of the 84 patients under study whose spinal cord trauma occurred above the sacral level. Talbot (4) assessed 408 patients and found an even lower value - only $10 \%$ of reported antegrade ejaculation.

Normal ejaculatory function, a primarily sympathetic phenomenon, consists in a complex and coordinated sequence of striated and smooth muscular contractions, which results in the antegrade emission and expulsion of sperm. The dorsal nerve of the penis transmits the afferent impulse produced by the tactile stimulation through the pudendal nerve to the cerebral centers. The efferent stimulus follows, occurring through the anterolateral column of the spinal cord until it reaches the sympathetic ganglionic chain (T10 to L2), the hypogastric plexus anterior to the aorta. Short postganglionic fibers divide into branches and reach the prostate, vasa deferentia and seminal vesicles. Adrenergic neurons stimulate the emission of sperm into the posterior urethra, while the bladder neck closes simultaneously, which prevents retrograde ejaculation. Through the somatic innervation (S2-S4), involuntary contractions of the periurethral musculature (bulbocavernous and ischiocavernous muscles) and the pelvic floor cause the expulsion of seminal fluid through the distal urethra distal, thus completing the ejaculatory event.

\section{Methods for Assisted Ejaculation}

Penile vibratory stimulation (PVS) and rectal probe electro-ejaculation (RPE) are methods currently used for this purpose $(3,22-27)$. The vibratory stimulation was first reported by Sobrero et al. (23) in 1965 as a method for inducing ejaculation in humans. In PVS, a vibratory device is placed in contact with the glans and frenulum preputii in order to stimulate ejaculation. Devices with high-amplitude movement $(>2.5 \mathrm{~mm})$ have shown better results when compared with low amplitude devices $(<2.5 \mathrm{~mm})$, with success rates of $60 \%$ to $80 \%$ and $30 \%$ to $40 \%$ respectively $(28,29)$. Since it is a non-invasive method, the process can be used at home by the patient himself, with no need for medical assistance. Due to the low local tactile sensitivity, patients should be instructed 
towards intermittent and non-prolonged use to avoid penile damage. The PVS shows better results in men with spinal cord lesion located above the thoraciclumbar efferent center (T10-L2); that is, when the ejaculatory reflex arc remains intact.

Electro-ejaculation was described by Horne et al. (3) in 1948 and is used in cases where PVS fails. It has a higher success rate than PVS - about $90 \%$ to $100 \%$. It consists in introducing a rectal probe and applying direct electric stimulation on the sympathetic efferent fibers of the hypogastric nerve through the anterior rectal wall. The procedure is usu- ally well tolerated and only $5 \%$ of patients require sedation or anesthesia for reducing the discomfort. Inadvertent damage to rectal mucosa can occur, and the performance of rectosigmoidoscopy before and after the procedure is routinely recommended. An additional disadvantage is the fact that the procedure's execution is restricted to outpatient/hospital regimen and provides low quality semen (30) (Table-1).

In the presence of retrograde ejaculation, $\mathrm{pH}$ changes and potential infections make the vesical environment hostile to the ejaculate, thus demanding urine alkalinization 24-48 hours before the procedure. For

Table 1 - Results with vibratory ejaculation (PVS) and electro-ejaculation (RPE) for obtaining semen and pregnancy rate in patients with spinal cord trauma.

\begin{tabular}{|c|c|c|c|c|c|}
\hline Author & $\mathbf{N}$ & Lesion Level & Method & Ejaculation Rate & Pregnancy Rate \\
\hline Rutkowski et al. (22) & 113 & $\mathrm{NR}^{*}$ & $\begin{array}{l}\text { PVS } \\
\text { RPE }\end{array}$ & $\begin{array}{l}67 \% \\
97 \%\end{array}$ & $55 \%(17 / 31)$ \\
\hline Heruti et al. (25) & 84 & $\begin{array}{c}\text { Cervical - } 29 \\
\text { Thoracic - } 50 \\
\text { Lumbar - } 05\end{array}$ & RPE & $100 \%$ & $70 \%(18 / 23)$ \\
\hline Nehra et al. (26) & 78 & $\begin{array}{l}\text { Cervical } \\
\text { Thoracic }\end{array}$ & $\begin{array}{l}\text { PVS } \\
\text { RPE }\end{array}$ & $\begin{array}{l}44 \% \\
95 \%\end{array}$ & $63 \%(17 / 27)$ \\
\hline Hultling et al. (32) & 25 & $\mathrm{C} 2-\mathrm{L} 3$ & $\begin{array}{l}\text { PVS } \\
\text { RPE }\end{array}$ & $\begin{array}{l}\text { NR } \\
\text { NR }\end{array}$ & $64 \%(16 / 25)$ \\
\hline Sonksen et al. (59) & 28 & - & $\begin{array}{l}\text { PVS } \\
\text { RPE }\end{array}$ & $\begin{array}{r}79 \% \\
100 \%\end{array}$ & $32 \% \quad(9 / 28)$ \\
\hline Brindsen et al. (60) & 56 & C5 - L1 & $\begin{array}{l}\text { PVS } \\
\text { RPE }\end{array}$ & $\begin{array}{l}17,8 \% \\
62,5 \%\end{array}$ & $51 \%(18 / 35)$ \\
\hline Kolletis et al. (61) & 27 & $\begin{array}{c}\text { Cervical - } 10 \\
\text { Thoracic - } 16 \\
\text { Lumbar - } 1\end{array}$ & RPE & $100 \%$ & $40 \% \quad(2 / 5)$ \\
\hline Shieh et al. (62) & 10 & $\begin{array}{c}\text { T3-T12-9 } \\
\text { C6- } 1\end{array}$ & RPE & $100 \%$ & $80 \% \quad(8 / 10)$ \\
\hline Buch et al. (63) & 18 & - & RPE & $89 \%$ & $50 \% \quad(3 / 6)$ \\
\hline Bennett et al. (64) & 37 & Thoracic & RPE & $53 \%$ & $40 \% \quad(4 / 10)$ \\
\hline
\end{tabular}

$* N R=$ non-reported data . 
this, sodium bicarbonate is orally administered the day before surgery, or a conservative medium, such as modified human tubal fluid (HTF), is instilled into the bladder after its emptying. Retrograde ejaculate is collected by bladder catheterization (24). Patients undergoing RPE or PVS and with lesions located above the T6 level are more susceptible to autonomic dysreflexia and require continuous monitoring or previous prophylaxis, such as administration of $20 \mathrm{mg}$ of nifedipine 15 minutes before performing the procedure (31).

Alternative methods, such as sperm aspiration from the epididymis or testis by microsurgery or puncture, can be used as well (MESA - microsurgical epididymal sperm aspiration, PESA - percutaneous epididymal sperm aspiration, TESE - testicular sperm extraction, TESA - testicular sperm aspiration). They have the inconvenience of obtaining a small seminal volume and a low number of spermatozoa in relation to ejaculate, and these methods are reserved for cases with obstructive azoospermia or when both PVS and RPE have failed $(32,33)$.

\section{SPERM QUALITY}

The quality of the ejaculate is yet another additional obstacle for patients with SCT, even following successful sperm collection by the several methods described above. Despite the absence of agreement among authors, the number of spermatozoa in spinal cord-injured patients is believed to be normal and, contrary to the previous thinking, there is no progressive decline over the years following trauma if the men have proper urological follow-up. Brackett et al. (34) conducted one study with 125 patients victimized by SCT. They analyzed spermiograms collected at intervals of 1 to 12 weeks, with an average of 5 samples per patient, over 24 months. This study found no differences in the concentration, total number and motility of spermatozoa in the ejaculate in relation to the time lapsed. However, other authors have reported increased sperm fragility, low motility (mean of $20 \%$ in comparison with $70 \%$ in healthy patients) and the presence of necrospermia. No correlation was demonstrated between these findings and the lesion level, patient's age, time since the trauma, or frequency of ejaculations $(35,36)$. The exact moment where the seminal quality starts to de- cline is still an issue for further investigation; however, it can possibly occur during the first months following the spinal cord lesion. It is difficult to assess the patients during the acute phase of SCT because they lack the emotional and physical conditions that would allow them to participate in assisted reproduction procedures. Brackett et al. (35) described a low success index in assisted ejaculation for patients at less than 1 year from the trauma, and once the semen was obtained, there was a small amount of spermatozoa, making the assessment difficult during the acute period. In a prospective study, Mallidis et al. (37) assessed 7 men with SCT and identified a decline in semen quality starting 16 days after SCT, thus recommending seminal cryopreservation in the acute phase. Padron et al. (38) found that the effects of sperm freezing were similar both in healthy patients and those with SCT; that is, there was decreased motility ranging from $60 \%$ to $80 \%$ after thawing. Due to the inferior seminal quality in spinal cord-injured patients, there is no apparent advantage with routine seminal cryopreservation in this group of patients. The process would be indicated in specific cases, such as the patient's personal wish, difficulty of transporting the ejaculate to the assisted reproduction centers, or limitations in time coordination between sample collection and use (33).

\section{Causes of Low Sperm Quality}

The main hypotheses formulated to explain the low sperm quality in spinal cord-injured patient are increase in scrotal temperature, aggression resulting from methods used in bladder emptying, infrequent ejaculations, altered hormonal environment, leukospermia, urinary tract infections and factors in seminal plasma that regulate sperm motility (39-57).

\section{Scrotal Temperature}

The similarity in seminal changes observed among patients with SCT has stimulated the search for common factors that could explain them. The increase in scrotal temperature is basically due to a scrotal thermoregulatory change by the autonomic nervous system and to the long periods which such patients remain seated in wheelchairs. Early studies have established a correlation between the increase in scrotal temperature and the low motility of sper- 
matozoa. Wang et al. (39) identified an initial scrotal temperature $1.2^{\circ} \mathrm{C}$ higher among spinal cord-injured patients compared to the control group. On the other hand, Brackett et al. (40) analyzed 66 patients with SCT and 21 controls and did not identify any differences in scrotal temperature or in seminal quality.

\section{Frequency of Ejaculation}

Siosteen et al. (41) reported an increase in seminal volume and the total number of motile spermatozoa in 16 patients who presented repeated ejaculations for a period of 4 to 6 months. On the other hand, Sonksen et al. (36) did not identify any changes in seminal quality when assessing 19 patients for a 1year period on a weekly PVS program.

\section{Method of Urinary Bladder Drainage}

Rutkowski et al. (42) evaluated the ejaculate of patients with SCT and identified a better percentage of sperm motility in patients who used intermittent bladder catheterization compared to other methods (indwelling bladder catheter and suprapubic drainage), probably due to the lower rate of urinary infection.

\section{Endocrine Dysfunction}

Normality of the hypothalamus-pituitary-gonad axis is fundamental for normal sperm production. Brackett et al. (43) identified a normal hormonal pattern in spinal cord-injured patients. In turn, Naderi et al. (44) identified decreased LH and FSH levels, suggesting that this contributed to the seminal changes to some degree. However, Morton (45) suggested that such changes could be caused by sleep apnea, which is present in $40 \%$ of patients with SCT, and associated with hypogonadotropic hypogonadism.

\section{Leukospermia and Urinary Tract Infections}

Bacteriuria was described in $60-70 \%$ of annual tests in patients with SCT. Wolff et al. (46) reported the association between leukospermia and a decrease in the number and motility of spermatozoa. Ohl et al. (47) have also verified the association between urinary infections and poorer sperm quality. However, seminal improvement is limited following treatment, still maintaining lower levels than healthy patients.

\section{Seminal Plasma}

Several authors have investigated the role of seminal plasma as the cause of poor sperm quality. When mixed with spermatozoa from normal men, seminal plasma from patients with SCT promotes a decrease in their motility. Contrarily, the addition of seminal plasma from normal men improves sperm motility in patients with SCT (48). Spermatozoa collected from the vas deferens of patients with spinal cord lesions show higher motility when compared to those obtained from the ejaculate and seminal vesicles, suggesting that the worsening quality could be associated with factors that are present in prostate or seminal vesicle secretions $(49,50)$. Changes in the seminal plasma have been found following SCT installation, such as reduced levels of fructose levels, albumin, glutamic oxaloacetic transaminase, alkaline phosphatase and prostate-specific antigen (PSA), and increased levels of chloride $(51,52)$, reactive oxygen species (ROS) (53) and cytokine $(54,55)$. The low fructose concentration in the semen from patients with SCT, which is a major energy source for the spermatozoa, has been pointed out as a co-factor in asthenospermia. Reactive oxygen species such as superoxide anion, hydrogen peroxide, peroxyl and hydroxyl are being correlated with low viability and morphological changes in spermatozoa (56). High cytokines (54) indicate an immunological ground for infertility. Cohen et al. (55) reported improvement in sperm motility following cytokine inactivation by monoclonal antibodies. Anti-sperm antibodies have also been reported as a potential cause of low seminal quality due to their high titers in such situations (57).

\section{ASSISTED REPRODUCTION TECHNIQUES}

Due to their low seminal quality, spinal cordinjured patients undergoing sperm collection usually require assistance for achieving fecundation and consequently, fatherhood. Factors that help determine the method to be employed are the patient's seminal parameters, their partner's age, their wife's health conditions and the procedure costs. The most frequently used techniques are intrauterine insemination (IUI), in vitro fertilization (IVF), gamete intrafallopian trans- 
fer (GIFT) or zygote intrafallopian transfer (ZIFT) and intracytoplasmic sperm injection (ICSI) in the oocyte (58).

In IUI, the semen is processed and the spermatozoa are separated from the seminal plasma. The partner is monitored by ultrasound or urine tests in order to detect the moment when ovulation occurs. Spermatozoa are introduced into the uterus through a catheter. The seminal concentration should be superior to $5.0 \times 10^{6} / \mathrm{mL}$ following processing so that the technique can be used. Pregnancy rates oscillated from $8 \%$ to $12 \%$ per cycle. When seminal concentration is between 2 and 5 million, IVF, GIFT or ZIFT must be preferred. In IVF, spermatozoa are left with the ovules and, following fertilization, the embryos are transferred to the uterus, with pregnancy rates of $20 \%$ to $40 \%$. GIFT and ZIFT consist of transferring gametes or the zygote into the uterine tube. Due to the procedure's more invasive nature, they are currently little used. ICSI is the injection of a single spermatozoon into the ovule, with subsequent transfer to the maternal uterus following embryo formation. It is indicated in cases where the previously mentioned methods have failed and in those where the seminal concentration is lower than $2 \mathrm{X}$ $10 \% \mathrm{~mL}$. The success rate (by pregnancy) is also around $20 \%$ and $40 \%$. Few studies have reported pregnancy rates (pregnancy/number of couples), or fecundation rates (pregnancy/number of pregnancy trials) in spinal cord-injured patients with assisted reproduction methods, ranging from $32 \%$ to $80 \%$ $(22,25,26,32,59,60-64)$ (Table-1).

\section{CONCLUSION}

Difficulties leading the patient with SCT to infertility are being progressively transposed due to advances in research and technology area. Methods for treating erectile dysfunction (oral and injectable medication, vacuum devices and prosthesis) and ejaculatory dysfunction (PVS, RPE, MESA, PESA, TESA and TESE) have contributed to this. Current studies have tried to establish factors existing in the seminal plasma as being responsible for the low sperm quality, even if there are no definitive results as yet. Currently, assisted ejaculation and reproduction have tried to answer this deficiency and increase the chances of patients with SCT in reaching their goal of fatherhood.

\section{REFERENCES}

1. Monga M, Bernie J, Rajasekaran M: Male infertility and erectile dysfunction in spinal cord injury: a review. Arch Phys Med Rehabil. 1999; 80: 1331-9.

2. Munro D, Horne HW, Paull DP: Effect of injury to the spinal cord and cauda equina on the sexual potency of men. N Engl J Med. 1948; 239: 904-11.

3. Horne HW, Paull DP, Munro D: Fertility studies in the human male with traumatic injuries of the spinal cord and cauda equina. N Engl J Med. 1948; 239: 959-61.

4. Talbot HS: Sexual function in paraplegia. J Urol. 1955; 73: 91-100.

5. Linsenmeyer TA: Sexual function and infertility following spinal cord injury. Phys Med Rehabil Clin N Am. 2000; 11: 141-56.

6. Lue TF: Physiology of Penile Erection and Pathophysiology of Erectile Dysfunction and Priapism. In: Walsh PC, Retik AB, Vaughan Jr. ED, Wein AJ (eds.), Campbell's Urology, 8th ed. Philadelphia, WB Saunders. 2002; pp. 1591-1610.

7. Guttmann L, Whitteridge D: Effects of bladder distension on autonomic mechanisms after spinal cord injuries. Brain. 1947; 70: 361-404.

8. Karlsson AK: Autonomic dysreflexia. Spinal Cord. 1999; 37: 383-91.

9. Ramos AS, Samso JV: Specific aspects of erectile dysfunction in spinal cord injury. Int J Impot Res. 2004; 16 (Suppl 2): S42-5.

10. Padma-Nathan H, Giuliano F: Oral drug therapy for erectile dysfunction. Urol Clin North Am. 2001; 28: 321-34.

11. Sanchez Ramos A, Vidal J, Jauregui ML, Barrera M, Recio C, Giner M, et al.: Efficacy, safety and predictive factors of therapeutic success with sildenafil for erectile dysfunction in patients with different spinal cord injuries. Spinal Cord. 2001; 39: 637-43.

12. Derry F, Hultling C, Seftel AD, Sipski ML: Efficacy and safety of sildenafil citrate (Viagra) in men with erectile dysfunction and spinal cord injury: a review. Urology. 2002; 60 (Suppl 2): 49-57.

13. Del Popolo G, Li Marzi V, Mondaini N, Lombardi G: Time/duration effectiveness of sildenafil versus tadalafil in the treatment of erectile dysfunction in male spinal cord-injured patients. Spinal Cord. 2004; 42: 643-8. 
14. Strebel RT, Reitz A, Tenti G, Curt A, Hauri D, Schurch B: Apomorphine sublingual as primary or secondary treatment for erectile dysfunction in patients with spinal cord injury. BJU Int. 2004; 93: 100-4.

15. Bodner DR, Lindan R, Leffler E, Kursh ED, Resnick MI: The application of intracavernous injection of vasoactive medications for erection in men with spinal cord injury. J Urol. 1987; 138: 310-1.

16. Dietzen CJ, Lloyd LK: Complications of intracavernous injections and penile prostheses in spinal cord injured men. Arch Phys Med Rehabil. 1992; 73: 652-5.

17. Denil J, Ohl DA, Smythe C: Vacuum erection device in spinal cord injured men: patient and partner satisfaction. Arch Phys Med Rehabil. 1996; 77: 750-3.

18. Levine LA, Dimitriou RJ: Vacuum constriction and external erection devices in erectile dysfunction. Urol Clin North Am. 2001; 28: 335-41.

19. Montague DK, Angermeier KW: Penile prosthesis implantation. Urol Clin North Am. 2001; 28: 355-61.

20. Kimoto Y, Iwatsubo E: Penile prostheses for the management of the neuropathic bladder and sexual dysfunction in spinal cord injury patients: long term follow up. Paraplegia. 1994; 32: 336-9.

21. Master VA, Turek PJ: Ejaculatory physiology and dysfunction. Urol Clin North Am. 2001; 28: 363-75.

22. Rutkowski SB, Geraghty TJ, Hagen DL, Bowers DM, Craven M, Middleton JW: A comprehensive approach to the management of male infertility following spinal cord injury. Spinal Cord. 1999; 37: 508-14.

23. Sobrero AJ, Stearns HE, Blair JH: Technique for induction of ejaculation in humans. Fertil Steril. 1965; 16: 765-7.

24. Ohl DA: Electroejaculation. Urol Clin North Am. 1993; 20: 181-8.

25. Heruti RJ, Katz H, Menashe Y, Weissenberg R, Raviv G, Madjar I, et al.: Treatment of male infertility due to spinal cord injury using rectal probe electro-ejaculation: the Israeli experience. Spinal Cord. 2001; 39: 168-75.

26. Nehra A, Werner MA, Bastuba M, Title C, Oates RD: Vibratory stimulation and rectal probe electro-ejaculation as therapy for patients with spinal cord injury: semen parameters and pregnancy rates. J Urol. 1996; 155: 554-9.

27. Sonksen J, Ohl DA: Penile vibratory stimulation and electro-ejaculation in the treatment of ejaculatory dysfunction. Int J Androl. 2002; 25: 324-32.

28. Sonksen J, Biering-Sorensen F, Kristensen JK: Ejaculation induced by penile vibratory stimulation in men with spinal cord injuries. The importance of the vibratory amplitude. Paraplegia. 1994; 32: 651-60.
29. Ohl DA, Menge AC, Sonksen J: Penile vibratory stimulation in spinal cord injured men: optimized vibration parameters and prognostic factors. Arch Phys Med Rehabil. 1996; 77: 903-5.

30. Brackett NL, Padron OF, Lynne CM: Semen quality of spinal cord injured men is better when obtained by vibratory stimulation versus electro-ejaculation. J Urol. 1997; 157: 151-7.

31. Steinberger RE, Ohl DA, Bennett CJ, McCabe M, Wang SC: Nifedipine pretreatment for autonomic dysreflexia during electro-ejaculation. Urology. 1990; 36: 228-31.

32. Hultling C, Rosenlund B, Levi R, Fridstrom M, Sjoblom $\mathrm{P}$, Hillensjo T: Assisted ejaculation and invitro fertilization in the treatment of infertile spinal cord-injured men: the role of intracytoplasmic sperm injection. Hum Reprod. 1997; 12: 499-502.

33. Amador MJ, Lynne CM, Brackett NL: A guide and resource directory to male fertility following spinal cord injury/dysfunction. Miami, University of Miami. 2000; p. 34. (Miami Project to Cure Paralysis).

34. Brackett NL, Ferrell SM, Aballa TC, Amador MJ, Lynne CM: Semen quality in spinal cord injured men: does it progressively decline post-injury? Arch Phys Med Rehabil. 1998; 79: 625-8.

35. Brackett NL, Nash MS, Lynne CM: Male fertility following spinal cord injury: facts and fiction. Phys Ther. 1996; 76: 1221-31.

36. Sonksen J, Ohl DA, Giwercman A, Biering-Sorensen F, Skakkebaek NE, Kristensen JK: Effect of repeated ejaculation on semen quality in spinal cord injured men. J Urol. 1999; 161: 1163-5.

37. Mallidis C, Lim TC, Hill ST, Skinner DJ, Brown DJ, Johnston WI, et al.: Collection of semen from men in acute phase of spinal cord injury. Lancet. 1994; 343: 1072-3.

38. Padron OF, Brackett NL, Weizman MS, Lynne CM: Semen of spinal cord injured men freezes reliably. J Androl. 1994; 15: 266-9.

39. Wang YH, Huang TS, Lin MC, Yeh CS, Lien IN: Scrotal temperature in spinal cord injury. Am J Phys Med Rehabil. 1993; 72: 6-9.

40. Brackett NL, Lynne CM, Weizman MS, Bloch WE, Padron OF: Scrotal and oral temperatures are not related to semen quality of serum gonadotropin levels in spinal cord-injured men. J Androl. 1994; 15: 614-9.

41. Siosteen A, Forssman L, Steen Y, Sullivan L, Wickstrom I: Quality of semen after repeated ejaculation treatment in spinal cord injury men. Paraplegia. 1990; 28: 96-104. 
42. Rutkowski SB, Middleton JW, Truman G, Hagen DL, Ryan JP: The influence of bladder management on fertility in spinal cord injured males. Paraplegia. 1995; 33: 263-6.

43. Brackett NL, Lynne CM, Weizman MS, Bloch WE, Abae M: Endocrine profiles and semen quality of spinal cord injured men. J Urol. 1994; 151: 114-9.

44. Naderi AR, Safarinejad MR: Endocrine profiles and semen quality in spinal cord injured men. Clin Endocrinol (Oxf). 2003; 58: 177-84.

45. Morton A: Endocrine profiles and semen quality in spinal cord injured men. Clin Endocrinol (Oxf). 2003; 59: 534-5.

46. Wolff H, Politch JA, Martinez A, Haimovici F, Hill JA, Anderson DJ: Leukocytospermia is associated with poor semen quality. Fertil Steril. 1990; 53: 528-36.

47. Ohl DA, Denil J, Fitzgerald-Shelton K, McCabe M, McGuire EJ, Menge AC, et al.: Fertility of spinal cord injured males: effect of genitourinary infection and bladder management on results of electro-ejaculation. J Am Paraplegia Soc. 1992; 15: 53-9.

48. Brackett NL, Davi RC, Padron OF, Lynne CM: Seminal plasma of spinal cord injured men inhibits sperm motility of normal men. J Urol. 1996; 155: 1632-5.

49. Brackett NL, Lynne CM, Aballa TC, Ferrell SM: Sperm motility from the vas deferens of spinal cord injured men is higher than from the ejaculate. J Urol. 2000; 164: 712-5.

50. Ohl DA, Menge AC, Jarow JP: Seminal vesicle aspiration in spinal cord injured men: insight into poor sperm quality. J Urol. 1999; 162: 2048-51.

51. Hirsch IH, Jeyendran RS, Sedor J, Rosecrans RR, Staas WE: Biochemical analysis of electro-ejaculates in spinal cord injured men: comparison to normal ejaculates. J Urol. 1991; 145: 73-6.

52. Lynne CM, Aballa TC, Wang TJ, Rittenhouse HG, Ferrell SM, Brackett NL: Serum and semen prostate specific antigen concentrations are different in young spinal cord injured men compared to normal controls. J Urol. 1999; 162: 89-91.

53. de Lamirande E, Leduc BE, Iwasaki A, Hassouna M, Gagnon C: Increased reactive oxygen species formation in semen of patients with spinal cord injury. Fertil Steril. 1995; 63: 637-42.

54. Basu S, Abdalla TC, Ferrel SM, Lynne CM, Brackett $\mathrm{NL}$ : Inflammatory cytokine concentrations are elevated in seminal plasma of men with spinal cord injuries. J Androl. 2004; 25: 250-4.

55. Cohen DR, Basu S, Randall JM, Aballa TC, Lynne CM, Brackett NL: Sperm motility in men with spinal cord injuries is enhanced by inactivating cytokines in the seminal plasma. J Androl. 2004; 25: 922-5.

56. de Lamirande E, Gagnon C: Reactive oxygen species and human spermatozoa. I. Effects on the motility of intact spermatozoa and on sperm axonemes. J Androl. 1992; 13: 368-78.

57. Hirsch IH, Sedor J, Callahan HJ, Staas WE Jr: Systemic sperm autoimmunity in spinal-cord injured men. Arch Androl. 1990; 25: 69-73.

58. Borges E Jr, Mori MM, Antunes N Jr: Reprodução Assistida e Infertilidade Masculina. Consenso Brasileiro sobre Infertilidade Masculina. São Paulo, BG Cultural. 1999; pp. 69-74.

59. Sonksen J, Sommer P, Biering-Sorensen F, Ziebe S, Lindhard A, Loft A, et al.: Pregnancy after assisted ejaculation procedures in men with spinal cord injury. Arch Phys Med Rehabil. 1997; 78: 1059-61.

60. Brindsen PR, Avery SM, Marcus S, Macnamee MC: Trans-rectal electro-ejaculation combined with in-vitro fertilization: effective treatment of anejaculatory infertility due to spinal cord injury. Hum Reprod. 1997; 12: 2687-92.

61. Kolettis PN, Lambert MC, Hammond KR, Kretzer PA, Steinkampf MP, Lloyd LK: Fertility outcomes after electro-ejaculation in men with spinal cord injury. Fertil Steril. 2002; 78: 429-31.

62. Shieh JY, Chen SU, Wang YH, Chang HC, Ho HN, Yang YS: A protocol of electro-ejaculation and systematic assisted reproductive technology achieved high efficiency and efficacy for pregnancy for anejaculatory men with spinal cord injury. Arch Phys Med Rehabil. 2003; 84: 535-40.

63. Buch JP, Zorn BH: Evaluation and treatment of infertility in spinal cord injured men through rectal probe electro-ejaculation. J Urol. 1993; 149: 1350-4.

64. Bennett CJ, Ayers JW, Randolph JF Jr, Seager SW, McCabe M, Moinipanah R, et al.: Electro-ejaculation of paraplegic males followed by pregnancies. Fertil Steril. 1987; 48: 1070-2.

Received: December 12, 2004

Accepted: March 20, 2005

\section{Correspondence address:}

Dr. Homero Bruschini

Department of Urology, EPM, UNIFESP

Rua Napoleão de Barros, 715 / 2o. andar

São Paulo, SP, 04024-002, Brazil

Fax: + $55115572-6490$

E-mail: bruschi@attglobal.net 